\title{
MINERALOGIA DA FRAÇÃO ARGILA DE PERFIS DE SOLOS DA SERIE PIRACICABA 1
}

\author{
J.L.I. Dematt $\widehat{e}^{2}$ \\ T. Kinjo ${ }^{2}$ \\ A.C. Teixeira Mendes ${ }^{3}$
}

RESUMO

0 presente trabalho teve por finalidade 0 estudo mineralógico, da fração argila, da série Piracicaba (RANZANI et al. 9), pertencente à unidade de mapeamento Podzólico Vermelho Amarelo - variação Piracicaba (COMISSÃO DE SOLOS, 2).

Foram coletados, na ärea de ocorrência da série Piracicaba, quatro perfís de solos, designados por perfís $\mathrm{P}_{1}$, $\mathrm{P}_{2}, \mathrm{P}_{3}$ e $\mathrm{P}_{4}$. As amostras dos horizontes foram colhidas a partir da superfície do solo até a rocha. A fração argila foi separada por sedimentação, endo posteriormente, dividida em duas subfrações (centrifugação): 2 a 0,2 mícron e menor que 0,2 mícron, argila grossa e fina, respectivamente.

0 material obtido nestas duas frações, sofreu determinações químicas (\% de $\mathrm{K}_{2} \mathrm{O}$ e capacidade de troca de cátions) e determinaçoes de raio - X (obtenção de difratogramas, com au xílio do contador Geiger, e filmes, pelo método do pó).Através dêstes resultados, foi efetuado o reconhecimento dos minerais de argila assim como estimativa semiquantitativa.

A anālise mineralógica das frações argila grossa e fina, referentes à natureza e à quantidade dos minerais de argila indica o seguinte: o teor de ilita, na fração argila grossa é sempre maior do que $10 \%$, sendo que, em certos horizon tes, apresenta teor de $30 \%$ e mesmo $40 \%$. A montmorilonita e os minerais de 14 \& normalmente ocorrem com valores inferiores a 10\%. A caolinita é o mineral dominante nas duas frações argila, com teores sempre acima de $40 \%$.

TEntregue para publicaçao em 11/7/1968; trabalho realizado oom parte dos dados da Tese de Doutoramento apresentada à E.S.A. "Luiz de Queiroz" pelo Engo Agro José Luiz I. Demattê.

2 Cadeira de Solos e Agrotecnia - ESALQ.

3 Cadeira de Geologia e Mineralogia - ESALQ. 


\section{INTRODUÇÃO}

A finalidade dos estudos mineralógicos dos solos, e no caso particular da fração argila, é contribuir para o conheci mento de sua gênese, assim como para o julgamento do estado po tencial de um solo.

Para êste estudo, foi utilizado a série Piracicaba, per tencente a unidade de mapeamento Podzólico Vermelho Amarelo - variação Piracicaba, unidade esta largamente distribuida no Estado de são Paulo e no município de Piracicaba. Êste solo se desenvolve a partir de sedimentos argilosos, apresentando um re levo normal, suavemente ondulado. 0 horizonte $B$ normalmente apresenta côres avermelhadas. Os horizontes A, devido às caras teristicas de textura, estão muito sujeitos à erosão laminar, cuja ação frequentemente se traduz por perdas que atingem $o$ horizonte $\mathrm{A}_{2}$ e, muitas vêzes, horizontes mais profundos.

PAIVA NETO (3), em estudos qualitativos da fração argila de "solos do Corumbataí", observou através da difração de raios - X, que o quartzo ocorre em quantidade muito elevada, por vêzes, nota-se a presença de caolinita, todavia, em percentagem reduzida.

Trabalhos da COMISST̃O DE SOLOS (2), demonstraram que a fraça argila, dos horizontes $\Lambda_{p}$ e $E_{22}$ apresentam dominancia de quartzo seguida de minerais de argilla do tipo $1: 1$ e no $C$ apre sentaram dominância ainda de quartzo seguido de minerais de argila do tipo $1: 1$ e da gibbsita.

\section{MATERIAL E MÉTODO}

\section{Material}

Para o presente trabalho foram coletados quatro perfís representativos da série Piracicaba (RANZANI et al.9). Foram coletadas aproximadamente $5 \mathrm{~kg}$ de terra de cada horizonte, inclusive da rocha, que foram levadas ao laboratório e preparadas de acôrdo com as indicações de RANZANI e KIEHL (10). 
0 aparelho de raio - X utilizado, foi um de marca NOREL co, fabricado pela PHILLIPS Co. A fonte de radiação usada foí um tubo de cobre, com um filtro de níquel; a unidade de fôrça trabalhou com $50 \mathrm{KW}$ e $18 \mathrm{~mA}$, sendo S.F. $=4, M=1$ e T.C. $=8$; a velocidade de varredura foi de $20 \mathrm{~min}$. e, a velocidade do papel, 4\%/ polegada; o contador Geiger operou com voltagem de $1.500 \mathrm{~V}$. A camara de pó utilizada foi do tipo DEBYE-SCHERRER, diâmetro $114,6 \mathrm{~mm}$, empregando a disposição de filme STRAUMANISIEVINS.

\section{Método}

A remoção da matéria orgânica, do óxido de ferro livre e a separação da fração argila do solo foram realizadas de acôr do com os trabalhos de JEFFRIES e JACKSON (5). A argila foí separada em argila grossa (2-0,2 mícron) e argila fina (menor que 0,2 mícron) com o auxílio de uma super centrífuga Sharples, cujos raios são de $2,17 \mathrm{~cm}$ e $0,72 \mathrm{~cm}$. O revestimento do tubo foi feito com papel de acetato de celulost ie $0,012 \mathrm{~cm}$ de espes sura. A fração argila grossa foi separada empregando-se $30.00 \overline{0}$ rpm e a fraçao argila fina, $50.000 \mathrm{rpm}$.

Para obtenção dos filmes pelo método do pó, as amostras de argila foram preparadas com saturação de cálcio, segundo método proposto por JACKSON (4). A posterior montagem da amostra para difração de raios - $X$, pelo método do pó, foi feito de acôrdo com as recomendações de TEIXEIRA MENDES (11).

O preparo e montagem de amostras orientadas foi feito de acôrdo com o método descrito por JOHN, GRIM e BRADLEY (6). A amostra natural foi irradiada com um angulo de 20 a $2802 \theta$; a amostra aquecida ( $450 \% \mathrm{C}$ ) e a glicolada foram irradiadas com um ângulo de $2^{\circ}$ a $1402 \theta$.

A determinação da capacidade de troca de cátions e do potássio total, das frações argila grossa e fina, foram efetuados de acôrdo com os métodos propostos por GLORIA, CATANI E MATUO (3) e CHAPMAN e PRATT (1) respectivamente. 
Anais da E.S.A. "Luiz de Queiroz"

0 reconhecimento dos minerais de argila, presentes na fração argila do solo, foi feito utilizando-se dados sôbre capa cidade de troca de cátions, teores de $\mathrm{K}_{2} \mathrm{O}$, difratogramas e filmes. Os difratogramas foram interpretados de acôrdo com as recomendações de JOHN, GRIM e BRADLEY (6): a ilita foi identifica da pelos espaçamentos a $10,0,5,0$ e 3,3 $\AA$, espaçamentos êstés que não se alteram com os tratamentos de aquecimento e de glico lação; a caolinita a espaçamentos de 7,2 e $3,5 \AA$; a montmorilonita a 14 na amostra natural e translocação para 17 \& na glicolada; a clorita pelos espaçamentos basais a 14,0,7,0,4,8 e $3,5 \AA$, espaçamentos êstes que são eliminados com o aquecimento, com excessão do de 14,0 $\AA$; vermiculita a $14,0 \AA$ na amostra natural e translocação para 10,0 A na aquecida. Para os difratogramas que apresentaram persistência a 14,0 $\AA$ após os trata mentos de aquecimento e glicolação, reservamos a designação de "minerais de 14,0 $\AA$ ".

A anālise semiquantitativa foi baseada nos padrões foto grāficos de misturas sintéticas obtidos por TEIXEIRA MENDES(11). A estimativa do teor de ilita, além da comparação fotogrä́fica, foi feita como recomendam MEHARA e JACKSON (7): o teor dêsse mi neral foi estimado tomando-se como base que $10 \%$ de $\mathrm{K}_{2} 0$ corres $=$ ponde a $100 \%$ de ilita.

\section{RESULTADOS E DISCUSSÃO}

Os resultados das análises de $\mathrm{K}_{2} 0$, capacidade de troca de cátions e raios - X (difratogramas e filmes) efetuados em ca da um dos horizontes dos perfis estudados e destinados à caracterização dos minerais de argila, encontram-se nos Quadros 1 e 2 .

Observa-se que o teor de ilita (perfil $\mathrm{P}_{1}$ ), da fração argila grossa, é sempre superior a 20\%. Nos difratogramas indi cados nas fig. 1 e 2 , nota-se perfeitamente os picos caracterís ticos dêsse mineral, ou seja, a $10,0,5,0$ e $3,3 \AA$. A montmori lonita e os minerais do grupo de $14 \AA$ ocorrem nos horizontes $B_{1}$, $B_{21}$, $C$ e $A_{1}, B_{1}, B_{22}$ respectivamente, apresentando normalmente teores inferiores a $10 \%$. A caolinita ocorre com valôres sempre superiores a 40\%. A fração argila fina indica uma predominân cia dêste mineral (valôres acima de 40\%), seguida pela ilita, com quantidades superiores a $10 \%$. 


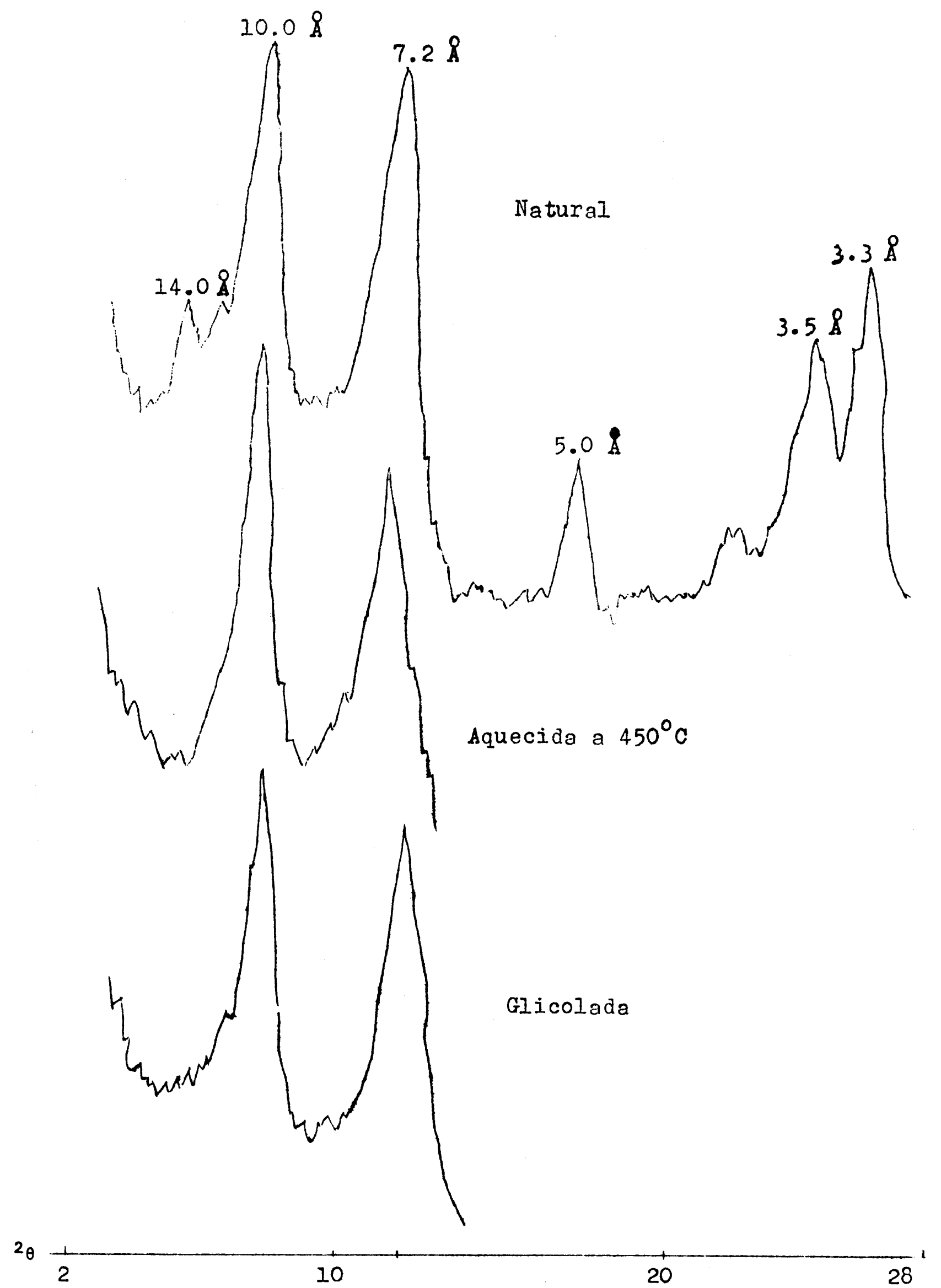

FIGURA 1 - Difração dos raios-X da fração argila grossa (Perfil $P_{1}$, horizonte $\mathrm{A}_{2}$ ). 

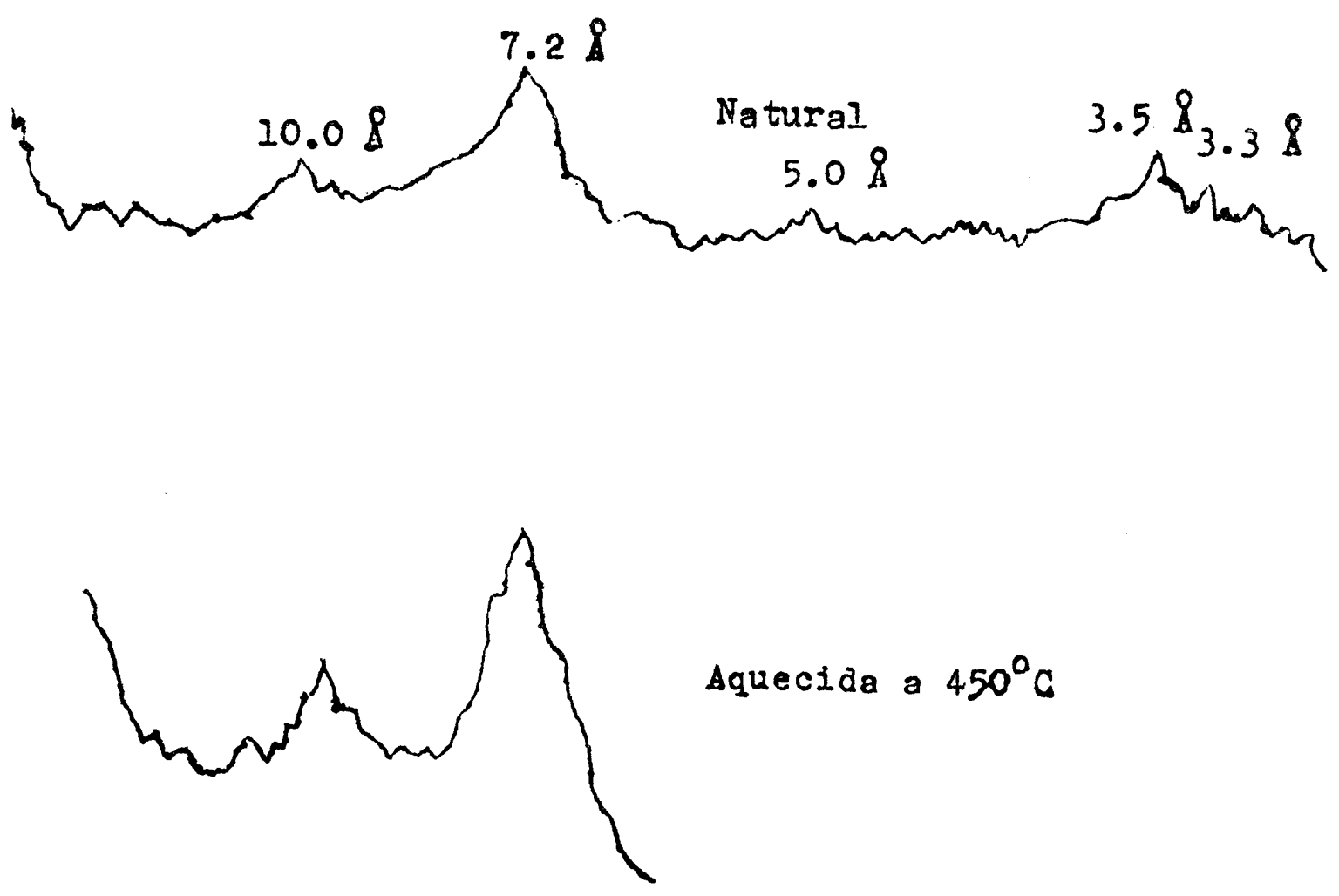

Aquecida a $450^{\circ} \mathrm{C}$

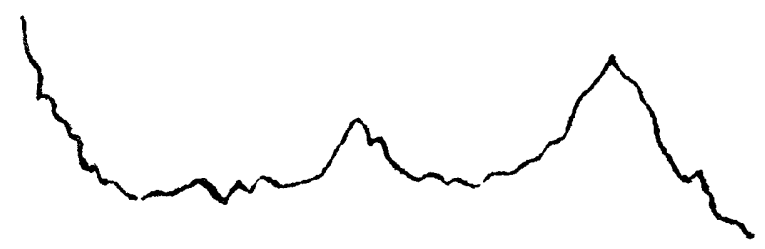

GIicolada

$2 \theta$

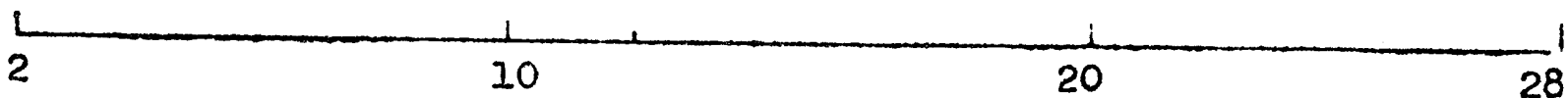

FIGURA 2 - Difração dos raios-X da fração argila fina (Perfil $P_{1}$, horizonte $\mathrm{A}_{2}$ ). 


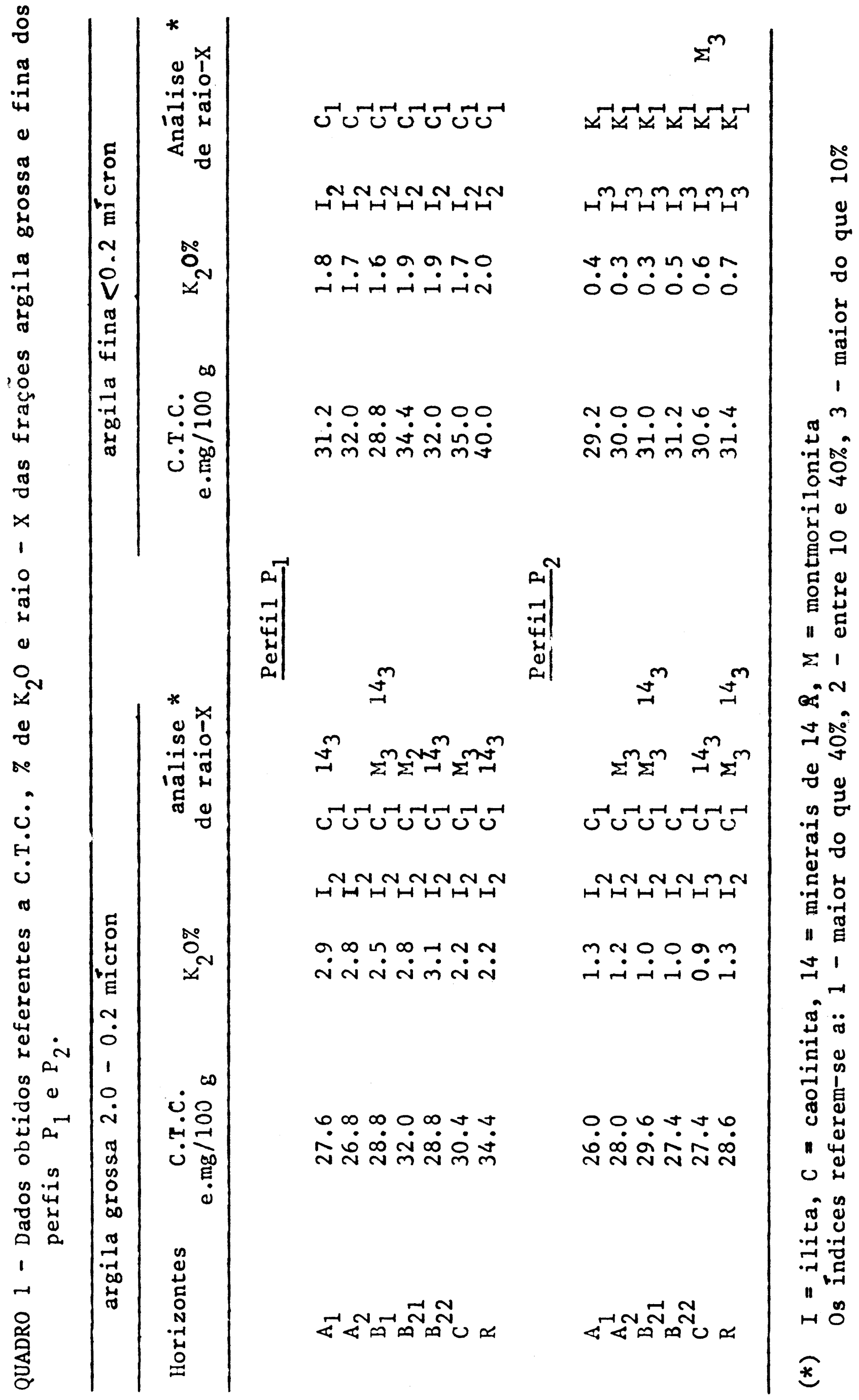




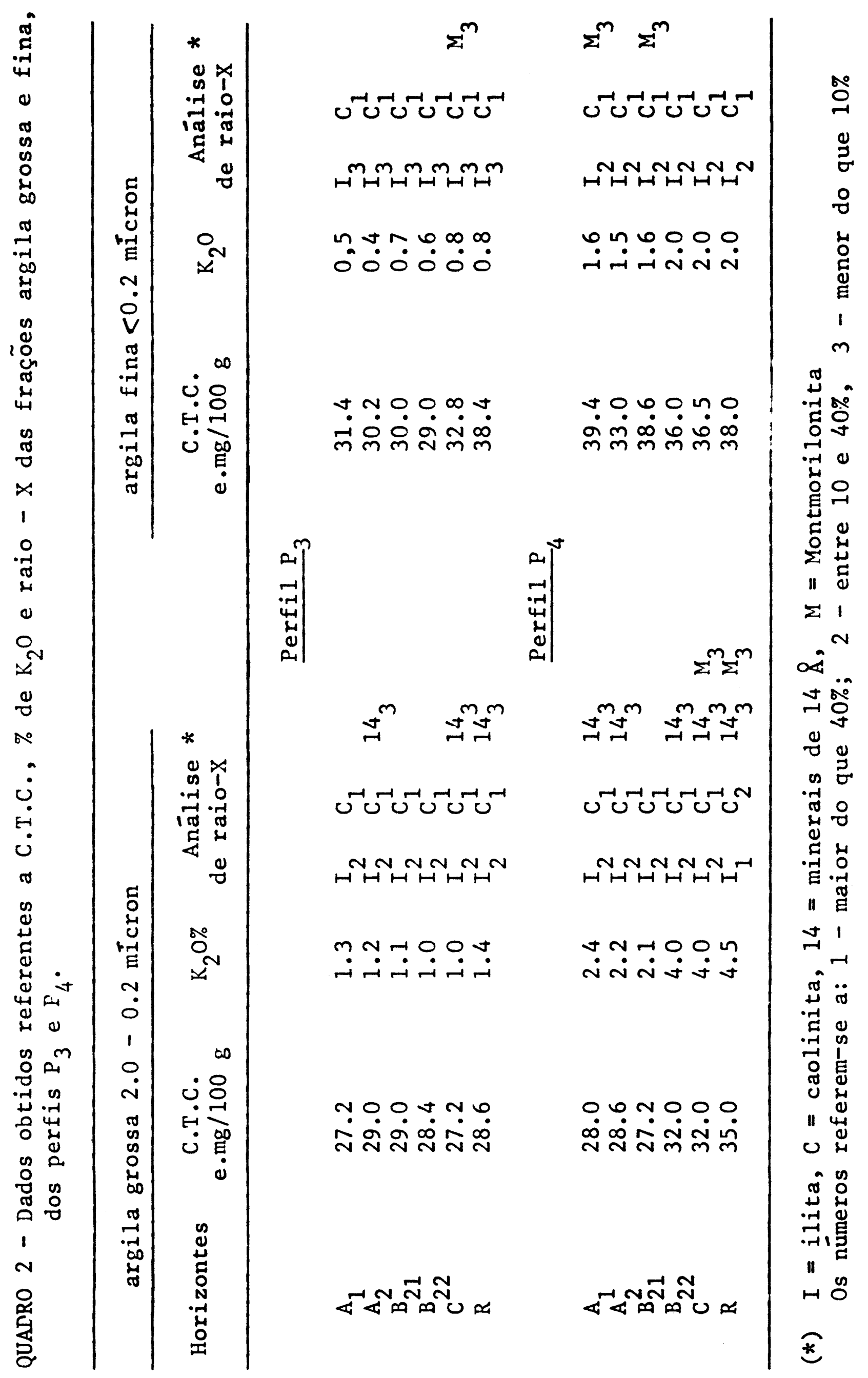


Os resultados referentes ao perfil $\mathrm{P}_{2}$, apresentados no Quadro 1, mostram a ocorrência das mesmas espécies mineralógicas assinaladas para o perfil $\mathrm{P}_{1}$, porém, com quantidades dife rentes. O teor de ilita, na frạça argila grossa, diminui sensivelmente com a profundidade do solo, aumentando ligeiramente na rocha. A montmorilonita aparece nos horizontes $A_{2}$ e $B_{21}$, com valores sempre inferiores a $10 \%$, sendo êste mineral Indicado pe 10 deslocamento do espaçamento basal de 14,0 para $17,0 \AA$ (fig. 3). A ocorrência dêsse mineral é ainda justificada pelo aumento dos valôres de capacidade de troca de cátions. A caolinita é o mineral dominante tanto na fração argila grossa como na fina, com teores acima de $40 \%$. Os difratogramas (fig. 3 e 4) mos tram os principais picos dos minerais citados.

0 teor de ilita, apresentado pelo perfil $\mathrm{P}_{3}$ (Quadro 2) para a fração argila grossa, diminui sensivelmente em profundidade, até atingir o material de origem, mantendo-se, porém, acị ma de $10 \%$. Nesta fração argila há predominância de caolinita, com valôres acima de $40 \%$. Os minerais do grupo de 14,0 \& ocorrem nos horizontes $A_{2}$ e $C$ na rocha subjacente, com teores inferiores a $10 \%$. Na fração argila fina, o mineral dominante ainda é a caolinita, seguida por quantidades men res de ilita e montmorilonita. Os difratogramas (fig. 5 e 6 ) apresentam os espaça mentos característicos dos minerais citados.

0 Quadro 2 mostra que o teor de ilita (perfil $\mathrm{P}_{4}$ ), na fração argila grossa, apresenta valôres sempre acima de $20 \%$, atingindo, nos horizontes mais inferiores, valôres de $40 \%$. Os espaçamentos apresentados pela ilita, são bem evidenciados nas figs. 7,8 e 9. A montmorilonita e os minerais do grupo de 14,0 $\AA$ mostram dados inferiores a $10 \%$. A quantidade de caolinita, na fração argila grossa, diminue em profundidade, apresentando, po rém, quantidades acima de $40 \%$ nos horizontes edafizados. A frá ção argila fina indica resultados semelhantes aos da fração mais grosseira, com dominância de caolinita. O teor de ilita é sempre superior a $10 \%$.

Através dos resultados obtidos referentes à natureza e à quantidade de minerais de argila existentes nas frações argila grossa e fina, verifica-se que os quatro perfis apresentam, alem da caolinita, outros minerais de argila como ilita, montmo rilonita e minerais de $14 \stackrel{\circ}{A}$. Êstes resultados, vem contradizer as afirmações de PAIVA NETO (8) e, em parte, as afirmações da COMISSÃO DE SOLOS (2). 


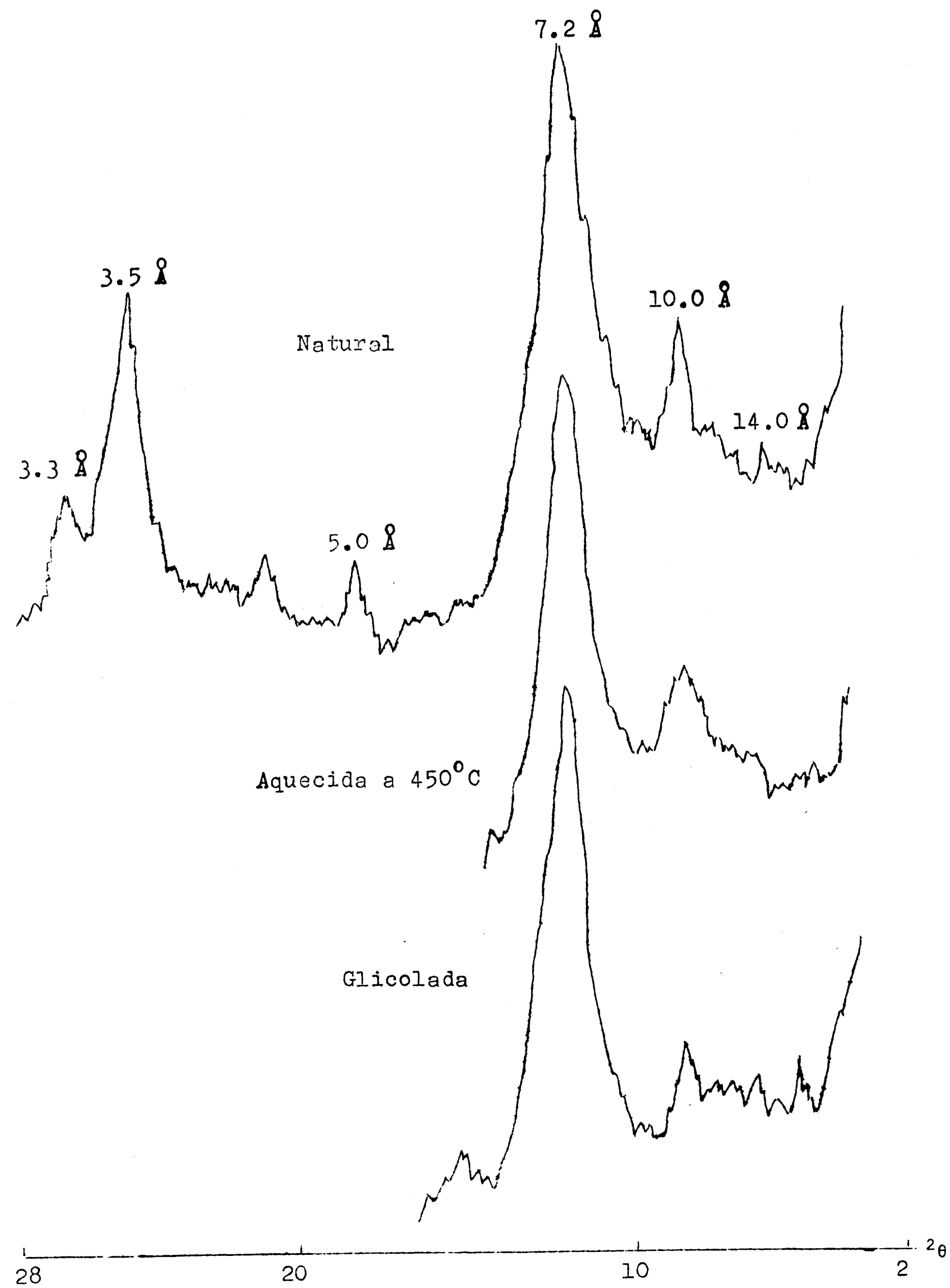

FIGURA 3 - Difração dos raios-X da fração argila grossa (Perfil $P_{2}$, horizonte $\left.B_{21}\right)$. 


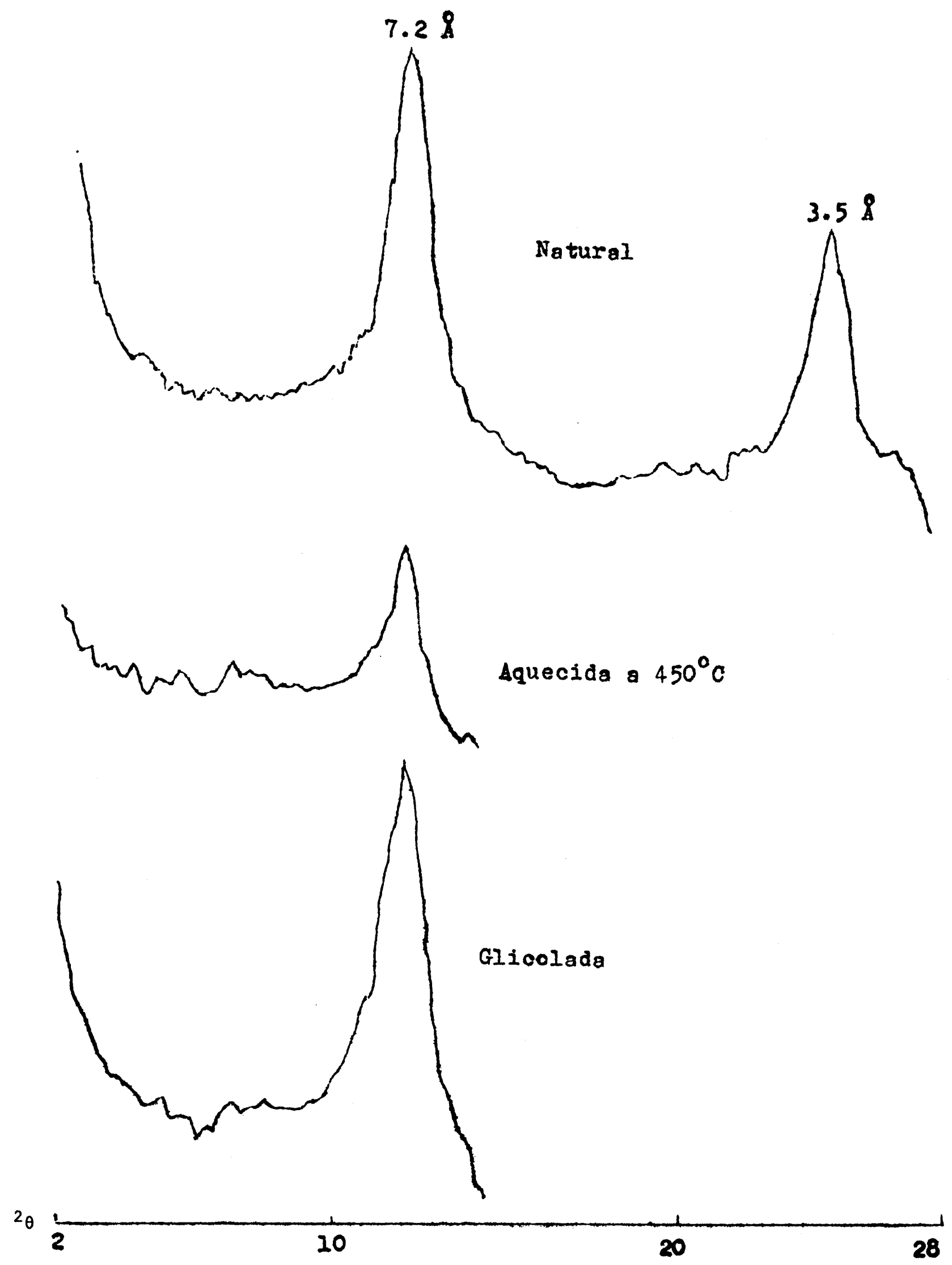

FIGURA 4 - Difração dos raios-X da fração argila fina (Perfil $P_{2}$, horizonte $B_{21}$ ). 


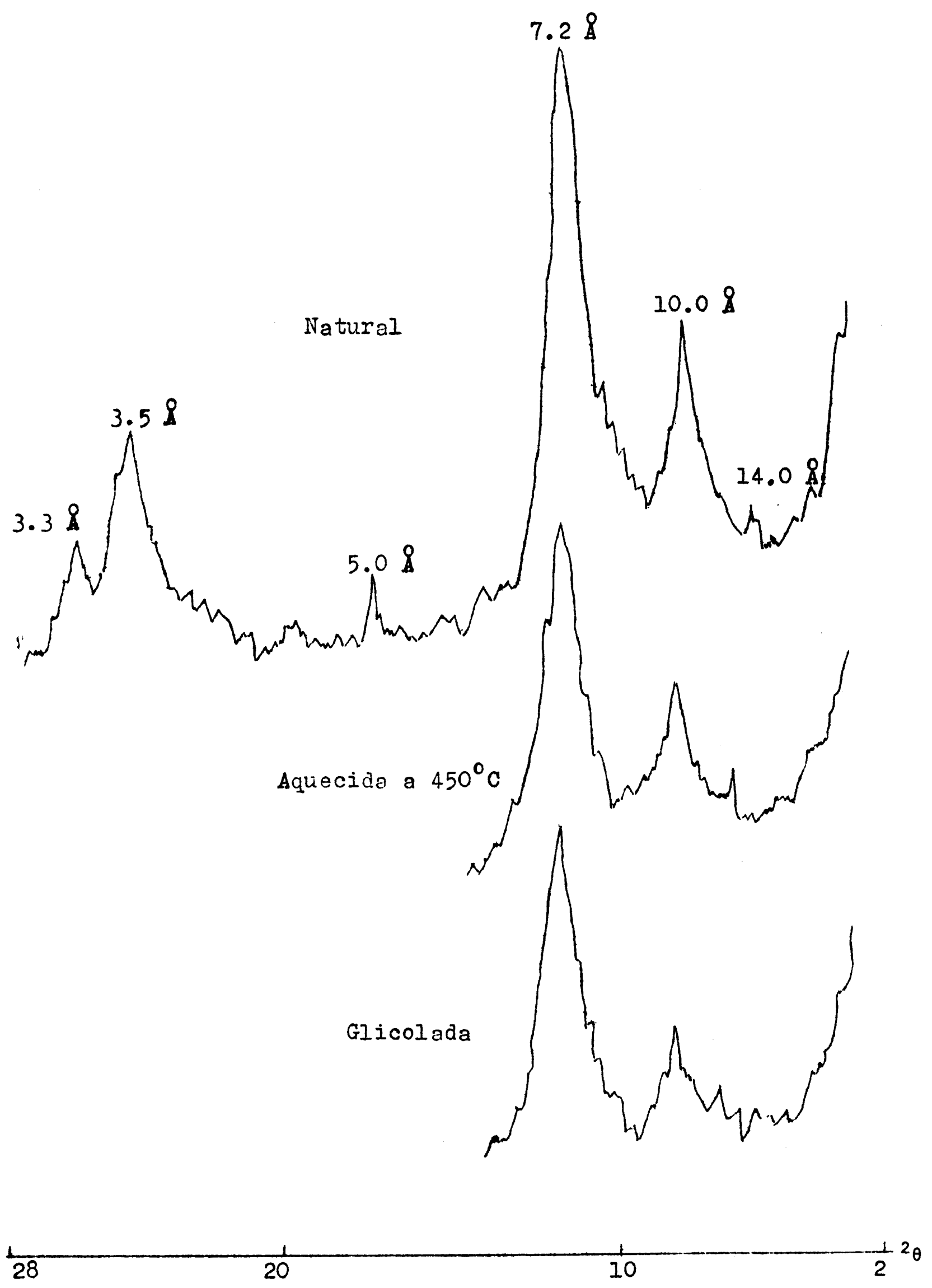

FIGURA 5 - Difração dos raios-X da fração argila grossa (Perfil $\mathrm{P}_{3}$, horieonte C). 

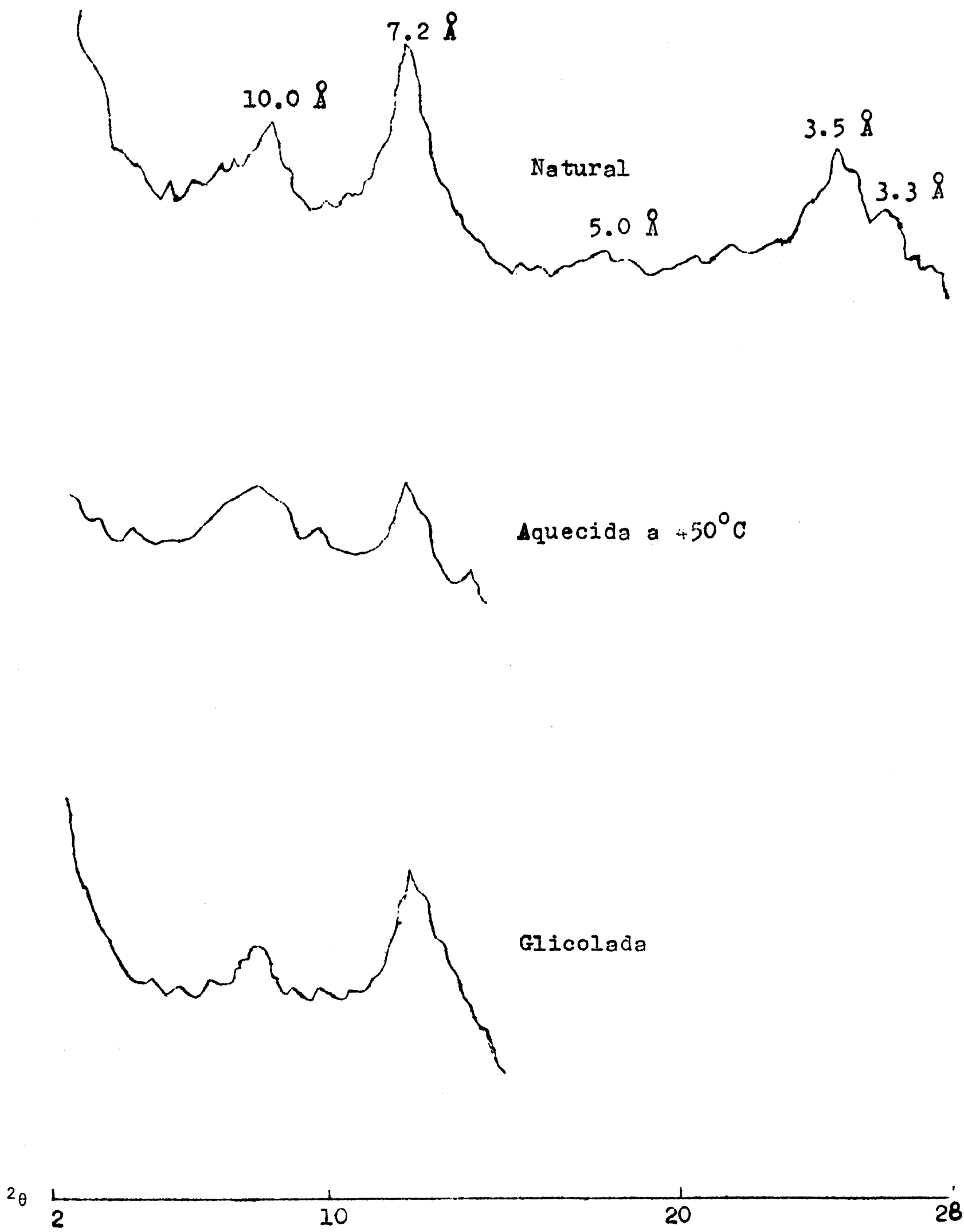

FIGURA 6 - Difração dos raios-X da fração argila fina (Perfil $P_{3}$, horizonte C). 

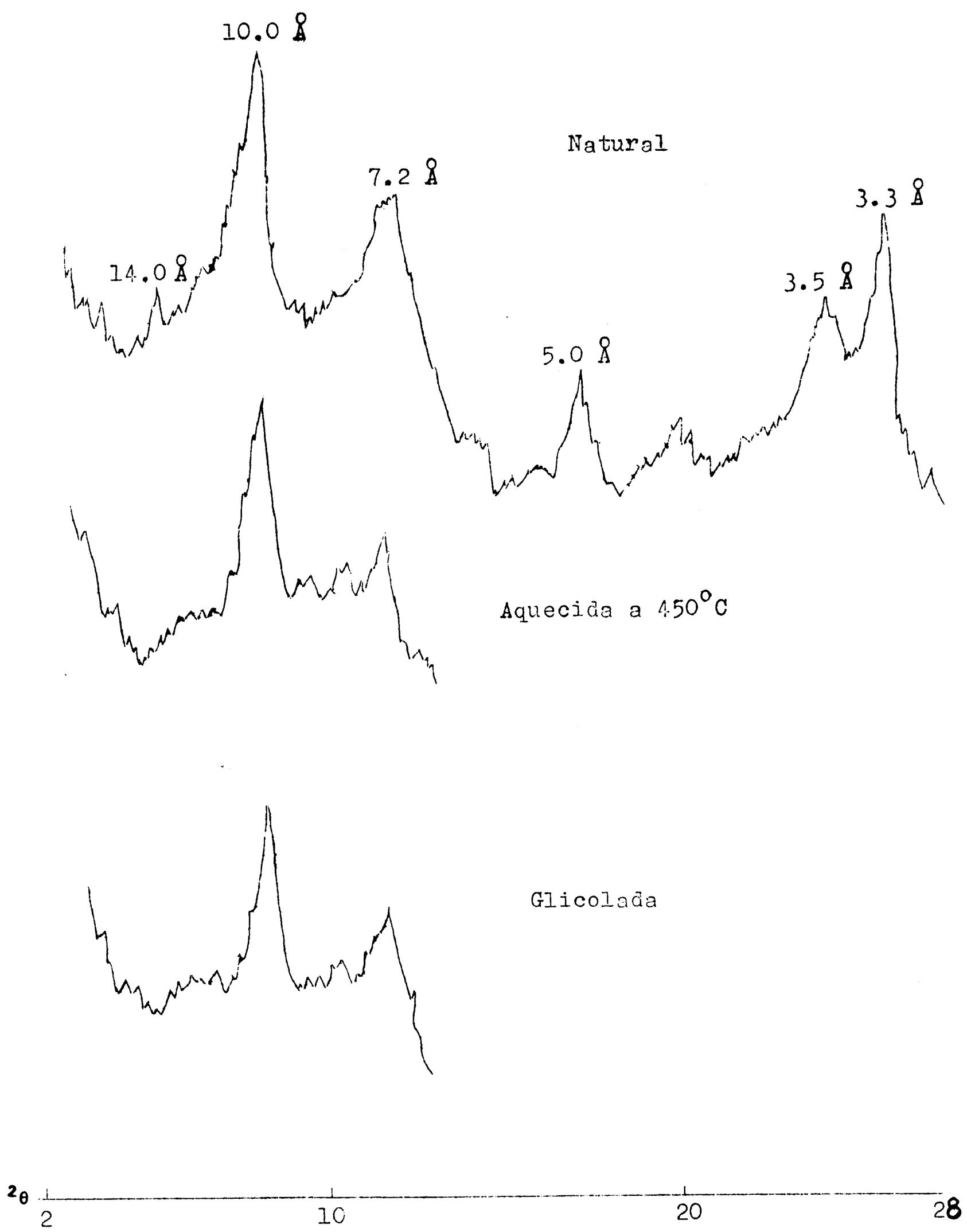

PIGURA 7 - Difração dos raios-X da fração argila grossa (Perfil $P_{4}$, horizonte $B_{21}$ ). 

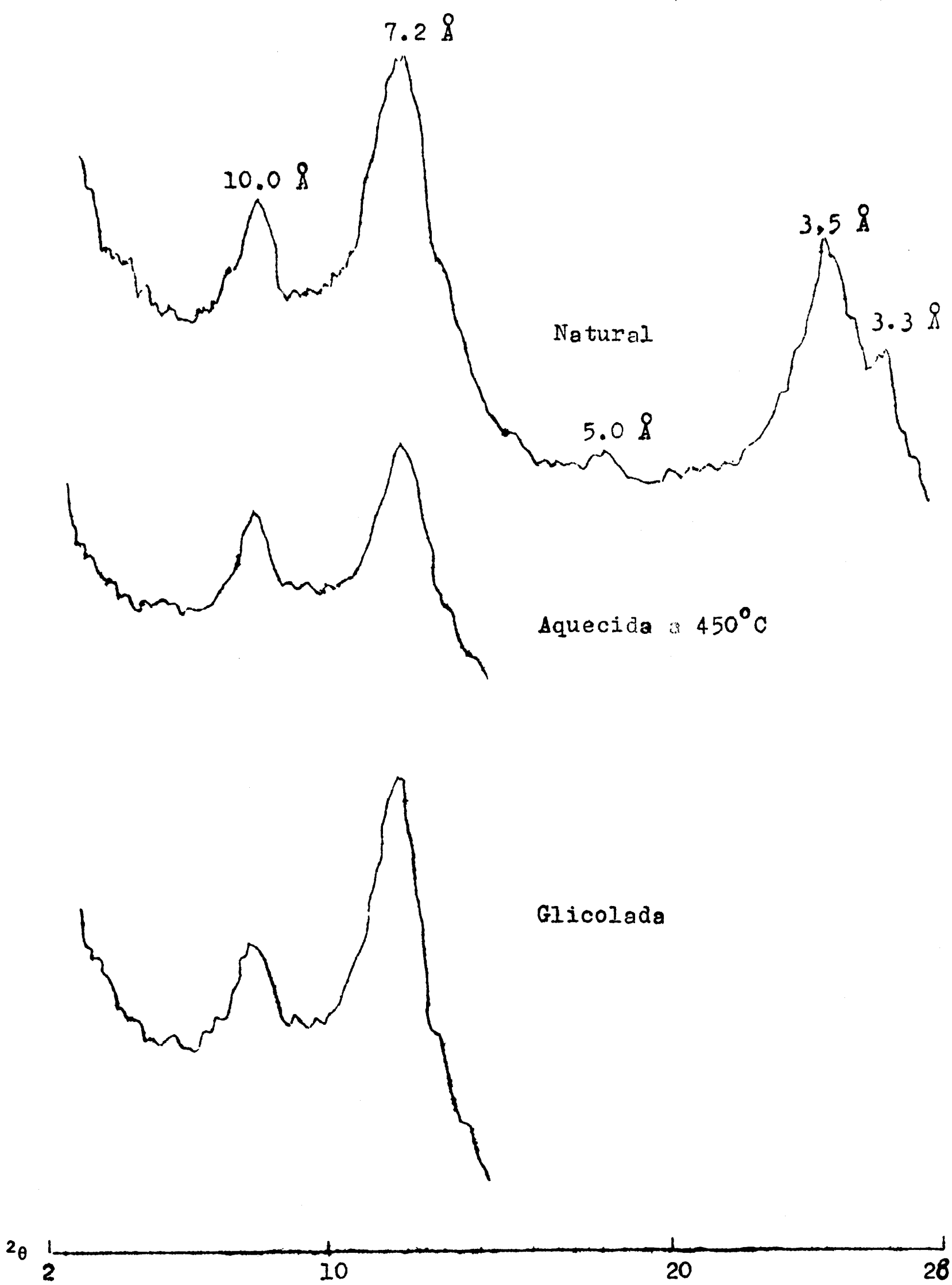

FIGURA 8 - Difração dos raios-X da fração argila fina (Perfil $P_{4}$, horizonte $B_{21}$ ). 


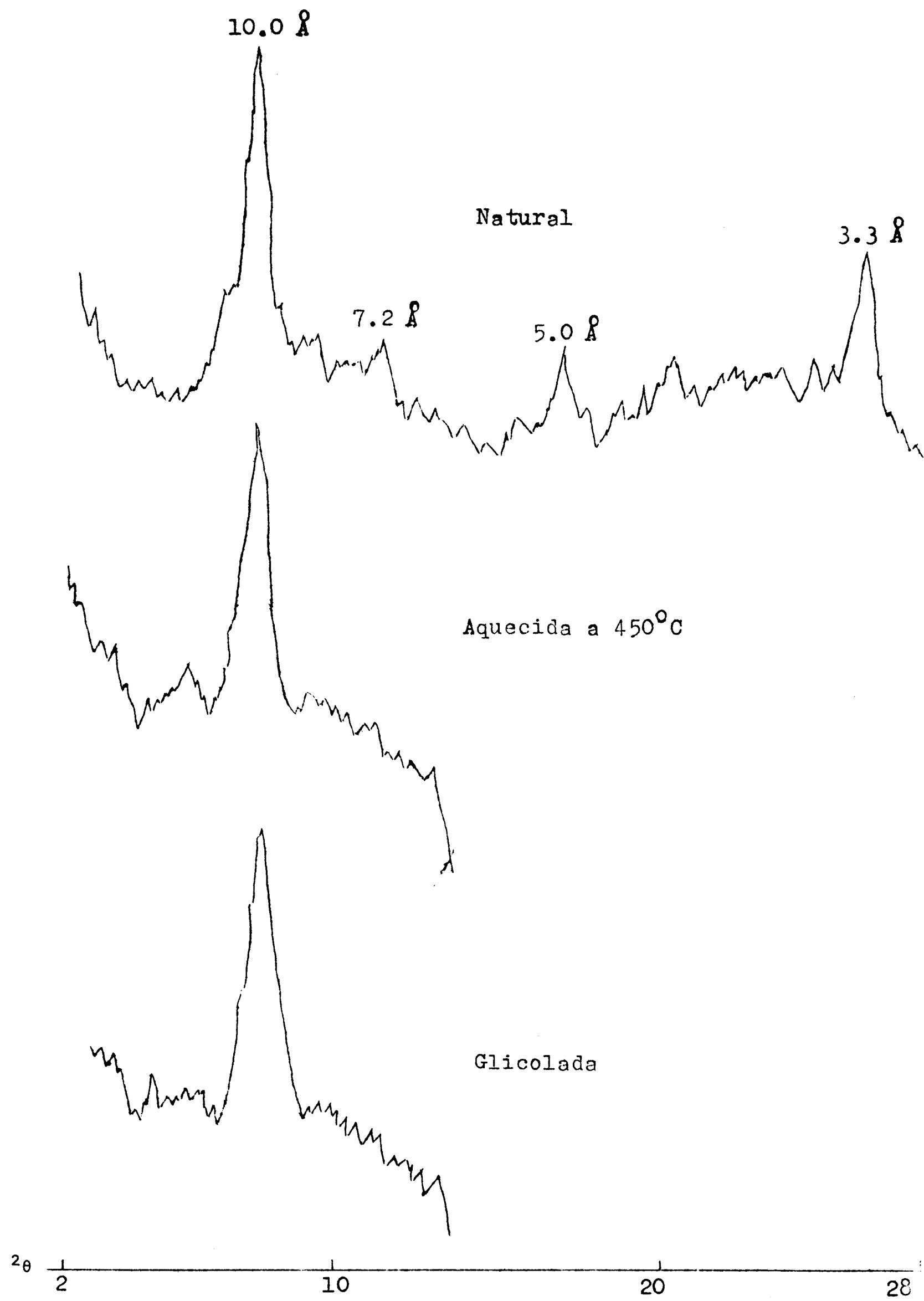

FIGURA 9 - Difração dos raios-X da fração argila grossa (Perfil $P_{4}$, horizonte R). 


\section{SUMMARY}

The purpose of this work was to study mineralogically the clay fraction of the Piracicaba series (RANZANI et al. 9). These soils belong to the Great Soil Group Red-Yellow Podzolic, Piracicaba variety.

Four profiles were collected within the areas where $\mathrm{Pi}$ racicaba series occur; these were labeled profiles $P_{1}$ through $\mathrm{P}_{4}$. The soil horizons were sampled individually in each profile from the surface down to the rock bed. The clay fraction was subdevided by centrifugation in coarse and fine clay with 0,2 micron as their limit of separation.

The identification of clay minerals in the two fractions and a semiquantitative analysis was done by interpretation of the results obtained from chemical analysis (\% of $\mathrm{K}_{2} \mathrm{O}$ and cation exchange capacity) and $X-r a y$ analysis (difratogram using a Geiger counter and films using the powder method).

The mineralogical analysis of the o clay fractions, relative to the nature and quantity of clay minerals, indicate the following: the content of illite in the coarse clay fraction is always higher than $10 \%$ and in certain horizons shows a content of $30 \%$ or even $40 \%$. The montmorilonite and the $14 \AA$ minerals normally occur with values lower than $10 \%$, Kaolinite is the mineral that occur in greater quantity in the two clay fractions with a content always higher than $40 \%$.

\section{LITERATURA CITADA}

1. CHAPMAN,H.D., and P.F. PRATT Methods of Analysis for Soils Plants and Waters - University of California. Division of Agricultural Sciences, 1961.

2. COMISSÃO DE SOLOS DO CNEPA Levantamento de Reconhecimento de Solos do Estado de São Paulo - Rio de Janeiro, Cen tro Nacional de Ensino e Pesquisas Agronómicas, Boletim $12,1960$.

3. GLORIA,N.A., R.A.CATANI e T.MATUO A determinação da capacidade de troca de cátions do solo pelo método do EDTA

- Revista da Agricultura, XL, 193-198. 1965 
4. JACKSON, M.L. Soil Chemical Analysis - Advanced Cource. Dept. of Soil, Univ. of Wis. Madison 6, Wis, 1956.

5. JEFFRIES,C.D., and M.L.JACKSON Mineralogical Analysis of Soils - Soil Sci. 68: 57-73, 1949.

6. JOHN,W.D., R.E.GRIM and W.F.BRADLEY Quantitative estimation of clay minerals by diffraction methods-Jour. Sedi mentary Petrology. 24: 242-251, 1954.

7. MEHARA,O.P., and M.L.JACKSON Constancy of the sum of mica unit cell potassium surface and interlayer sorption in vermiculite illite clays - Soil Sci.Soc.Amer.Proc. 23: 101-105, 1959.

8. PAIVA Neto, J.E. A "fração argila" dos solos do Estado de São Paulo e seu estudo roentgenográfico - Bragantia 2: $355-432$, 1942 .

9. RANZANI,G. et al. A série Piracicaba - Centro de Estudos de Solos. Nao publicado.

10 . e E.J.KIEHL Prática de Solos - E.S.A. "Luiz de Queiroz", U.S.P. - Piracicaba, 1959.

11. TEIXEIRA MENDES, A.C. Anālise quantitativa da fração argị la de Solos - Tese de Doutoramento. E.S.A. "Luiz de Queiroz" - U.S.P., 1967. 